ISSN 1981-416X

Licenciado sob uma Licença Creative Commons

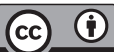

\title{
Postura cartográfica nos percursos de pesquisa
}

\author{
Cartographic stance in search paths
}

Postura cartográfica en rutas de búsqueda

\section{Maria de Lourdes da Silva Neta ${ }^{[a]}$, Antonio Germano Magalhães Junior ${ }^{[b]}$, Sarah Bezerra Luna Varela Machado ${ }^{[b]^{*}}$}

[a] Instituto Federal de Educação, Ciência e Tecnologia do Ceará, Fortaleza, CE, Brasil

[b] Universidade Estadual do Ceará, Fortaleza, CE, Brasil

\section{Resumo}

As descrições dos percursos metodológicos das pesquisas são relevantes pelo fato de apontarem os caminhos percorridos pelos investigadores na exploração dos objetos, na constituição das aprendizagens e na superação de dificuldades no/do pesquisar. Nosso escrito teve por objeto as narrativas de sujeitos sobre a cartografia como postura investigativa adotada por um grupo de pesquisadores na área de Educação. Objetivamos compreender as experiências de percurso constituídas por professores/pesquisadores em formação que utilizam a postura cartográfica como atitude perante o exercício da pesquisa. A pesquisa de cunho qualitativo recorreu às dimensões bibliográfica e documental e utilizou os relatórios dos pesquisadores, atentando para três pistas: dificuldades, estratégias e

*MLSN: Doutora em Educação, e-mail: lourdes.neta@ifce.edu.br AGMJ: Doutor em Educação Brasileira, e-mail: germano.junior@uece.br SBLVM: Mestre em Educação, e-mail: sarah.varela@uece.br 
aprendizagens. A postura cartográfica motivou o espírito científico e a incerteza na busca do conhecimento no percurso formativo do grupo de pesquisadores.

Palavras-chave: Cartografia. Percursos Metodológicos. Experiências.

\begin{abstract}
The description of the methodological pathways of the research is relevant and points out the paths taken by researchers in the exploration of objects, in the constitution of learning and in overcoming difficulties in the research. Our paper had as object of study the narratives of subjects about cartography as an investigative stance adopted by a group of researchers. We aim to understand the course experiences constituted by professors / researchers in formation that use the cartographic posture as an attitude towards the exercise of the research. The qualitative, bibliographical and documentary research used the reports of the researchers looking for three tracks: difficulties, strategies and learning. The cartographic posture motivated the scientific spirit and the uncertainty in the pursuit of knowledge in the formation of the researchers' group.
\end{abstract}

Keywords: Cartography. Methodological Paths. Experiences.

\title{
Resumen
}

Descripciones de vías metodológicas de la investigación son relevantes para el hecho de señalar las rutas recorridas por los investigadores sobre el funcionamiento de objetos, en el establecimiento de aprendizaje y superación de las dificultades en la búsqueda. Nuestro escrito fue objeto de narrativas sobre la cartografía como postura investigativa adoptada por un grupo de investigadores en el área de la educación. Nuestro objetivo es entender las experiencias por supuesto formado por profesores/investigadores en formación usando el cartográficos postura como una actitud hacia la práctica de la investigación. La investigación cualitativa naturaleza apeló a dimensiones bibliográficas y documental, utiliza los informes de los investigadores que buscan a tres carriles: dificultades y estrategias de 
aprendizaje. La posición cartográfica incitó el espiritu científico y la incertidumbre en la búsqueda del conocimiento en el curso de formación del grupo de investigadores.

Palabras clave: Cartografía. Vías Metodológicas. Experiencias.

\section{Introdução}

Este artigo discute sobre a escuta e escrita cartográfica de pesquisa. Objetivamos compreender as experiências de percurso constituídas por professores/pesquisadores em formação que utilizam a postura cartográfica como atitude perante o exercício da pesquisa.

Trata-se de uma investigação cuja abordagem é qualitativa, possibilitando discutir a utilização da postura cartográfica em pesquisas na área de Educação, especialmente na temática docência universitária, retratando trajetórias de formação e orientação na graduação e Pós-graduação stricto sensu de um grupo constituído por nove pesquisadores que se reuniu no período de janeiro de 2016 a agosto do ano de 2017, semanalmente, para estudar os escritos de Gusmão (2012), Morin (2015), Passos, Kastrup e Escócia (2015), Rolnik (2014) e Magalhães Junior (2009), dentre outros, com o intento de compreender a postura cartográfica e de relatar suas dúvidas, anseios e dificuldades em relação às pesquisas.

Nosso objeto de estudo foi as narrativas e escritos elaborados por estes sujeitos pesquisadores sobre as possíveis dificuldades enfrentadas no decorrer de suas investigações, as estratégias de superação e as aprendizagens proporcionadas aos profissionais em formação. Os referidos pesquisadores trabalharam em um projeto financiado pelo Conselho Nacional de Desenvolvimento Científico e Tecnológico (CNPq), por meio de aprovação no Edital da Chamada Universal Ministério da Ciência, 
Tecnologia e Inovação (MTCI)/CNPq no 14/2014. A referida investigação, denominada pesquisa macro, realizou uma cartografia das relações de saber/poder, formação, práticas e saberes dos professores dos cursos de licenciatura de uma Instituição de Ensino Superior Pública que trabalham especificamente as disciplinas destinadas à formação pedagógica.

As publicações sobre a formação daqueles que formam outros profissionais, ou seja, dos professores formadores, são frequentes no meio acadêmico. Para Tardif (2000), estes estudos têm sido enfatizados nos últimos 30 anos, por causa dos debates que questionam a eficácia da formação profissional vivida nas universidades - em particular, a formação de professores. Por esse motivo, justificamos a elaboração desse escrito de nossa pesquisa, pois acreditamos que os resultados podem auxiliar aqueles que buscam trilhar caminhos parecidos, sabendo que um mesmo caminho percorrido em dois momentos distintos, ou mesmo por duas pessoas diferentes, pode proporcionar experiências diversificadas. Não pretendemos demonstrar um caminho, mas a possibilidade de, ao conhecer caminhadas, ajudar na tomada de decisões de como realizar seu próprio percurso. Utilizamos o que aqui definimos como postura cartográfica, atitudes de posicionamento investigativo de orientador e orientandos, compreendendo que os pesquisadores em formação possivelmente assumirão o papel de orientadores no desenvolvimento da carreira docente no ensino superior.

Organizamos o artigo em quatro seções. A primeira descreve o contexto da realização do estudo, a postura metodológica e os sujeitos participantes. A segunda apresenta e discute as dificuldades encontradas pelos pesquisadores. A seção seguinte delineia as estratégias de superação. Por fim, destacamos as aprendizagens vivenciadas pelos investigadores. Concluímos o texto desenhando um mapa de significados destas diferentes trajetórias que encontraram em comum a postura investigativa de pesquisar cartografando. O leitor é convidado a seguir conosco nestas pistas metodológicas que auxiliam na realização de estudos nas ciências humanas, de forma específica na educação. 


\section{A postura cartográfica}

Como todo "bom" utilizador da postura cartográfica, começamos descrevendo o contexto da realização deste estudo para, em seguida, interpretarmos as escolhas vivenciadas. Somos um grupo formado por professores pesquisadores, e objetivamos realizar estudos que possam colaborar com melhorias na educação.

Somos muitos e diferentes. Alguns de nós ainda estamos fazendo formação de graduação em cursos de licenciatura (três), outros são mestrandos (dois) ou doutorandos (quatro) e há um que consideramos nosso orientador, mas que também se encontra em formação. Possuímos formações básicas distintas, idades variadas, orientações sexuais diferentes. Muitas coisas não são iguais, mas temos algo em comum: estarmos envolvidos em uma pesquisa que nos junta, desafia, educa e faz-nos divergir, rir e angustiar.

Todos nós estamos exercitando a labuta da pesquisa em uma Instituição de Ensino Superior (IES) pública, com todas as vantagens/ possibilidades/liberdades que podemos desfrutar, mas com os limites financeiros e estruturais bem característicos da referida instituição. O que nos une como pesquisa é a busca por compreender a constituição dos saberes, práticas de ensino e formação de professores que trabalham nos cursos de licenciatura da IES investigada.

Durante a realização da pesquisa macro, decidimos também nos colocar em questionamento e tornarmo-nos sujeitos de pesquisa. Daí o intuito de realizar o exercício de escuta das narrativas dos pesquisadores participantes da pesquisa macro que utilizam a cartografia como postura metodológica nas suas investigações. Coletamos suas narrativas, seguindo as orientações da ética, recorrendo às indicações da Resolução $n^{\circ} 510$, de 07 de abril de 2016.

Para respeitar o princípio de anonimato dos respondentes da pesquisa, atribuímos um número a cada um dos sujeitos que colaboraram com seus relatos. Os doutorandos receberam os números de 1 a 4, os mestrandos 5 e 6 e os bolsistas de iniciação científica de 7 a 9. Foi solicitado a 
cada um que relatasse, por escrito, suas experiências no exercício da pesquisa, considerando: as dificuldades enfrentadas, as estratégias de superação e as aprendizagens proporcionadas aos profissionais em formação que estão utilizando a Postura Cartográfica como referencial metodológico e teórico para a pesquisa em Educação.

Descrever as narrativas destes sujeitos e analisá-las segundo uma postura cartográfica é como apresentar um diário ainda com páginas em branco. Fazer uma pesquisa utilizando o referencial da cartografia é partir com propósitos e pistas (PASSOS; KASTRUP; ESCÓCIA, 2015). Temos ciência do que almejamos, mas não iniciamos com uma precisão de métodos e estratégias que limitem a descoberta do novo e uma tomada e retomada de caminhos. Cartografar possibilita experiências que enlaçam pesquisadores, fontes, sujeitos, instrumentos de coleta e tudo mais que faz parte do métier de quem se faz pesquisador.

A utilização da postura cartográfica como orientadora de percurso coloca o pesquisador imerso no processo, não somente como executor da ação de pesquisar, mas como um ente que apresenta suas percepções e sensações vividas no encontro com seu campo e objeto de estudo. A relação pesquisador e campo de pesquisa não se constitui como espaço de neutralidade, mesmo sabendo que devemos cuidar em não "conduzirmos" a pesquisa para os caminhos que acreditamos ser os melhores em relação aos seus resultados. Muitos pesquisadores iniciam suas investigações procurando confirmar suas "verdades", proporcionando a manutenção do que acreditam ser a explicação para o entendimento do real, não ficando somente em análises teoréticas (GUSMÃO, 2012). Quando descrevemos nossos percursos, escolhas, dúvidas, na verdade tudo que sentimos e fazemos nas nossas "trilhas" da pesquisa, estamos possibilitando uma atenção a princípios de fidelidade com a realidade, procurando demonstrar o que sentimos, mas não podendo alterar os resultados encontrados com o objetivo de satisfazer nossas "verdades".

Partindo das premissas anteriormente mencionadas, podemos definir o que nomeamos de postura cartográfica. Quando mencionamos o termo cartografia e citamos alguns autores que utilizam esta categoria, 
devemos deixar explícito que partimos buscando compreender o que os referidos pensadores definem e usam como cartografia, mas o que estamos realizando é a execução de uma atitude perante o exercício de pesquisar. Não estamos buscando utilizar a cartografia e sim o exercício de uma postura cartográfica.

\section{O que significa esta postura metodológica? A cartografia é,}

[...] diferentemente do mapa, é a inteligibilidade da paisagem em seus acidentes, suas mutações: ela acompanha os movimentos invisíveis e imprevisíveis da terra aqui, movimentos do desejo, que vão transfigurando, imperceptivelmente, na paisagem vigente (ROLNIK, 2014, p. 62).

A cartografia se faz à medida que os percursos se desvelam. Dessa maneira, a escolha das estratégias investigativas também acontece durante o processo de conhecimento das trajetórias a serem cartografadas. Levamos, na bagagem, a disponibilidade de ouvir, de perceber, e alguns poucos questionamentos, já que esses também surgem no contexto da (re)constituição da cartografia de cada um. Assim, corroboramos com Rolnik (2014) quando afirma que cartografar vai além de desenhar uma realidade estática: significa descrever procedimentos, delinear escolhas, compreender, por intermédio do conhecimento dos processos e percursos pessoais e profissionais dos sujeitos.

A referida forma de se posicionar perante a pesquisa deve ser exercida por orientador e orientando. Isso não significa apresentar modelos rígidos e métodos procedimentais a serem seguidos de uma forma que coloque em risco a essência do que aqui postulamos. Os envolvidos na pesquisa devem estar em constante ato de perguntar-se, escrevendo e discutindo suas escolhas, sejam elas de fontes, métodos, arcabouços teóricos e tudo mais que faz parte do desenho de uma pesquisa. Compreendemos que ter uma postura cartográfica significa descrever minuciosamente o que fez, por que fez e como fez, colocando-se no processo e refletindo suas escolhas. Um trabalho acadêmico que parte de uma descrição minuciosa dos atos e desejos vivenciados possibilita diálogos mais sinceros. Procurar 
mostrar o que fez e o que conduziu o fazer é postura de quem está aberto a críticas e novas possibilidades. "Dizer-se": esta seria uma boa definição, em uma só palavra, de alguém que exercita uma Postura Cartográfica.

Esta postura exige cuidados por parte do pesquisador que a assume na realização de sua investigação. Primeiramente, ele deve estar atento a detalhes em tudo que investiga e sempre disposto a saber mais, descrevendo minuciosamente o que encontrou, como encontrou e o que tais achados acrescentaram em suas reflexões sobre a labuta da pesquisa em exercício. Parece um ato corriqueiro e normal para quem faz uma investigação acadêmica, mas não é. Os encontros entre orientador e orientando são muitas vezes palco de questionamentos que indagam sobre os porquês de escolhas realizadas e o que tais caminhos proporcionaram em relação à modificação no pensar e fazer do pesquisador em formação.

Depois de mais de vinte anos orientando trabalhos acadêmicos, encontramos a necessidade de saber mais sobre as decisões tomadas. Escutar justificativas. Motivar descrições minuciosas. Arguir sobre escolhas teóricas. Auxiliar no ato reflexivo de alguém que precisa saber explicar e defender as escolhas de caminhos trilhados. Acreditamos que os que praticam a Postura Cartográfica vivenciam crises permanentes de certezas, sentem-se como órfãos que buscam abrigo; o desconforto fortalece o espírito do pesquisador. Com estas últimas palavras, lembramo-nos dos escritos de Bachelard (1996) quando descreve como deve ser o espírito do pesquisador. Isto é ter uma postura cartográfica. Relatar o que pensou quando fez, refletir e descrever o caminho que tomou. Enfim, dizer-se.

O exercício de orientar o desenvolvimento de uma pesquisa, durante um curso de formação, requer uma dupla intenção, trabalhar para que o pesquisador desenvolva suas atividades, objetivando a realização de uma investigação caracterizada pelos princípios da cientificidade e paralelamente auxiliar na formação de alguém que exerce a atitude de pesquisar e deve aprender no seu fazer, inclusive para ser orientador. Não é tarefa fácil, mas necessária. O orientador deve procurar conhecer e auxiliar para que o 
orientando busque incessantemente refletir sobre suas escolhas, estimulando que as atitudes realizadas possam e devam ser descritas, explicadas e devidamente fundamentadas considerando as necessidades apresentadas.

Os textos produzidos pelos participantes da pesquisa nos levam a refletir sobre os posicionamentos de cada sujeito. Vamos separar as escrituras de acordo com as categorias instituídas para constituição dos relatos e faremos uma análise por categoria (MINAYO, 2001). Para melhor compreendermos os relatos realizados é necessário descrever como o referido grupo trabalhou na pesquisa. Ocorreram encontros de todos os pesquisadores envolvidos, foram sugeridas leituras e temáticas a serem discutidas e depois dos estudos realizados foram promovidos encontros em que cada pesquisador relatou suas opiniões sobre os estudos feitos e as relações que foram constituídas com o seu objeto e objetivo de pesquisa.

O exercício é possibilitar a constituição de tramas, enlaçando o que se estudou com o que se está vivenciando no exercício da investigação e pensar-se neste contexto, explicando as decisões tomadas, justificando cada caminho percorrido, incertezas, achados, desejos, procurando sentido e dando significado ao que se pensa e faz. Um exercício de postura cartográfica. O sentimento de angústia é constante, a dúvida deve ser amiga do pesquisador (MAGALHÃES JUNIOR, 2009). Foi solicitado a cada sujeito da pesquisa que relatasse sobre: as dificuldades encontradas, as estratégias de superação e as aprendizagens proporcionadas quando se exercita a postura cartográfica. Vamos, então, trilhar as narrativas destes sujeitos.

\section{As dificuldades encontradas}

Um estado de desconforto foi o que caracterizou os relatos dos sujeitos participantes da pesquisa em relação às dificuldades encontradas. $\mathrm{O}$ aspecto de novidade nas leituras realizadas e a complexidade de alguns textos estudados marcou a escrita dos pesquisadores. "Os primeiros encontros foram tão contemplativos como assustadores, pois eu começava a ser inserida num mundo 'novo e desejado', o ingresso no curso de doutorado [...] ansiosa por novas descobertas teóricas e práticas" (Pesquisador 1). 
O início de um processo formativo com o encontro de temas e leituras ainda não realizadas apresentou dificuldades e sentimentos de incerteza, tão necessários no exercício da busca pelo conhecimento (POPPER, 2002). Buscando retratar algumas dificuldades no tocante à postura cartográfica, apontamos as explanações de um dos pesquisadores,

As dificuldades de lidar com essa postura de pesquisa se relacionam com o rompimento de modelos anteriores. Nós ficamos muito arraigados em modelos e a cartografia propõe um rompimento de modelos. Porque o que se ensina é que cada pesquisa vai demandar um jeito de cartografar diferente. Pois as pesquisas envolvem sujeitos, contextos e estudos diferentes. Então, cartografar também vai ser diferente. Esta ausência de um modelo foi uma dificuldade para mim. Por eu ter uma postura mais sistemática, a busca por um modelo me afeta, pois a presença dele tornaria mais fácil para encaixar minha investigação. Só que o diferencial do cartografar não é o se encaixar num modelo, mas é o desenhar uma trama, como um mapa de relações e trocas. Vários nós de um rizoma que formam um todo repleto de complexidade e que faz parte da vida dos seres humanos e que, portanto, faz parte da nossa pesquisa, pois ela está na área das ciências humanas e na educação. $\mathrm{O}$ desafio mais marcante foi desvencilhar-se de um modelo (Pesquisador 3).

A formação acadêmica muitas vezes é marcada por modelos e posicionamentos ideológicos que podem arrefecer o que chamamos de espírito científico. O contato com explicações teóricas que apresentam um mundo constituído por certezas, um mundo de totalidades e não considerando as complexidades que devem ser devidamente consideradas e analisadas, constituem uma armadilha epistemológica que devemos minimamente considerar para não incorrermos na busca de afirmar e sim de tentar negar o que acreditamos conhecer. Um eterno colocar em dúvida.

A cartografia rompe os padrões de pesquisa que estamos acostumados nas universidades, em dissertações e entre outros. Desconstrói tudo aquilo que achamos não poder ser realizado em uma pesquisa, pelo menos comigo foi assim, não desvalorizando de nenhuma maneira a responsabilidade de fazer uma pesquisa responsável e fidedigna (Pesquisador 8). 
Como se tratava de uma linha de pesquisa em que eu não tinha uma certa "segurança", por não ter leituras sobre o foco da pesquisa e nem ter experiência em pesquisa, muito menos onde a pesquisa tivesse a cartografia como o modelo de pesquisa. Afinal, como estudante de geografia em licenciatura, eu escutava esse nome CARTOGRAFIA DAS RELAÇÕES, e logo vinha a mente fazer um plano de mapas topográficos ou temáticos com essas relações. Até o dia de algumas reuniões e depois de muitas leituras, que pude entender o que é a tal cartografia que foi dita. Ela se tratava de colocar o pesquisador como parte da pesquisa, é ele descrever o que viu, sentiu, pensou, percebeu, é se colocar dentro da pesquisa, as suas percepções, isso seria a cartografia, é uma descrição minuciosa do processo da pesquisa. A partir disso pude entender o que levaria a relação da cartografia da pesquisa com a cartografia dita em geografia. Pois a cartografia é uma descrição de todo o relevo, onde até a altimetria tem que ser dita, o detalhe tem que ser mostrado e dito no mapa, localizá-lo e dizer de onde é o recorte espacial e qual o período. Informações importantes que irão dizer o passo a passo do processo. Assim foi como pude entender as relações da cartografia quando usada em pesquisa, e a cartografia em geografia (Pesquisador 9).

Podemos verificar que o exercício da postura cartográfica possibilitou o estado de incerteza e a necessidade de buscar mais.

Relatar dificuldades, estratégias de superação e aprendizagens, implica uma parada para reflexão. Dessa vez, não sobre as leituras feitas ou sobre os conceitos aprendidos; mas sobre a minha interação com esses conteúdos e a contribuição destes para com a construção de conhecimentos necessários à minha trajetória acadêmica e ao desenvolvimento da minha pesquisa. O que, em princípio, parecia fácil, na verdade revelou-se uma tarefa difícil de ser cumprida. Qual a dificuldade em passar para o papel os roteiros seguidos em uma viagem? Talvez a dificuldade esteja em ser uma viagem a um universo até então desconhecido. Tal qual Alice, encontro-me, também, tentando adequar-me às mudanças e apropriar-me de conceitos a partir de uma perspectiva nunca antes imaginada. E, para falar sobre o percurso do meu encontro com a cartografia, faz-se necessário apresentar aspectos relevantes que caracterizam a minha trajetória nesse semestre (Pesquisador 4). 
O exercício inicial normalmente se amálgama com a incerteza e logo a necessidade de encontrar um estado de conforto. A definição de métodos precisos pode ser uma estratégia para a busca de normas e padrões que proporcionem certezas e projeções de produtos finalizados. Mas não é isto que o exercício da Postura Cartográfica preconiza. Sabemos que precisamos de diretrizes, mas não de modelos previamente instituídos.

Porém, o contato que tive com a Cartografia na Iniciação Científica rompeu com a ideia que tinha anteriormente quando defendeu a necessidade de não recortar a realidade para afirmar a teoria. Mas, utilizar esta para discutir a percepção daquela. Além disso, a forma como essa percepção deve acontecer na Cartografia é diferenciada, pois leva o pesquisador a ficar atento aos detalhes, aos registros, às pistas e às relações entre os acontecimentos e entre as pessoas. Eu diria que lembra muito a etnografia, no sentido que essa convida o pesquisador a vivenciar um contexto para tentar descrever uma realidade e dar a sua interpretação (Pesquisador 7).

O que me ajudou a tranquilizar as inquietações foi entender que eu já estava cartografando. As reuniões de grupo, os debates entre os colegas, os estudos nas disciplinas, as leituras sobre esta proposta investigativa, o aprender com outras pesquisas, os embates de ideias, tudo isso já era objeto a ser cartografado, afinal nós já estávamos pesquisando. Eu tinha muito a perspectiva de que eu só iria cartografar quando eu estivesse em campo, mas na verdade todo processo de pesquisa é permeado pela cartografia, por esse mapa de relações, de intersubjetividades, de estudos, debates e questionamentos. E assim eu percebi que de fato eu já estava cartografando (Pesquisador 3).

Colocar-se em estado de dúvida, formulando novas perguntas a cada afirmativa realizada, encontrar-se órfão de suas certezas. Procurar investigar incessantemente. Os relatos demonstram que as reuniões conduzidas, através de relatos de percursos e dúvidas de caminhos a serem seguidos, foram construtivas e guias na constituição dos mapas que conduziam aos caminhos na pesquisa. 
Ao ler os textos de Deleuze e Guattari pela primeira vez, duvidei de minha capacidade de compreensão. Recorri a outras leituras, especificamente no campo da Psicologia, e devorei como quem devora um alimento em busca de compreender o que esses autores diziam. Diante de tantas possibilidades, consegui compreender, mesmo que minimamente, o pensamento dos referidos autores. A leitura de Deleuze e Guattari provocou em mim um deslocamento na forma como eu penso. Foi assim que me senti. A cartografia afetou-me profundamente: acordo e durmo pensando nela; em como posso melhorar a escrita do texto, em como ela está conduzindo os passos na pesquisa, que pista seguir ao adentrar o campo, e por aí vai (Pesquisador 5).

O ato de se colocar na incerteza não é atitude fácil de ser experienciada; requer maturação e experimentação. Conforme Diniz (2012), os deslocamentos nos inquietam, afugentam nossas certezas temporárias, mas nos movem rumo ao desconhecido.

Entre a estranheza e a dúvida foram apresentadas nos encontros de orientação as informações básicas acerca da cartografia, sabemos que usamos um termo oriundo da Geografia, devido ao que representa o ofício do cartógrafo e suas minúcias, no qual desenvolveremos um desenho meticuloso que ajudará a localizar, a compreender as dimensões da formação docente e suas especificidades, uma vez que a diretriz cartográfica se constitui por pistas que orientam o percurso da pesquisa considerando os efeitos do processo do pesquisar sobre o objeto investigativo, o pesquisador e seus resultados e que auxiliará na compreensão do objeto escolhido. Passamos a compreender que o termo cartografia será utilizado como uma significação particular, objetivando melhor fazer entender a forma do exercício de pesquisar que será utilizado no decorrer da investigação e auxiliará no meu percurso de formação de professor/pesquisador (Pesquisador 2).

As leituras iniciais sobre o conceito e uso da cartografia na pesquisa social foram fundamentais para a maturação e definição do que depois chamaríamos de postura cartográfica, diferenciado, mas ao mesmo tempo tendo como referência os escritos de Deleuze e Guattari (2004) e Rolnik (2014). 
No primeiro momento, eu achei uma proposta de pesquisa confusa e, ao mesmo tempo, ousada. Confusa porque ela quebrava paradigmas com relação ao que eu havia aprendido no decorrer da minha formação como professor e pesquisador. E ousada justamente por este rompimento de paradigmas [...]. O decorrer do caminhar, os passos que são dados são o foco. E isso me chamou bastante atenção e me ajudou a repensar as minhas práticas como estudante de doutorado. Portanto, os dois elementos que considero de aprendizagem foram essa ousadia e a diferente postura investigativa que foca no processo, no passo a passo e tudo isso pode ser cartografado (Pesquisador 3 ).

Para o pesquisador, uma reflexão permanente e devidamente relatada e interpretada, conjuntamente com os achados e procedimentos realizados, constitui um amálgama fértil para alguém que precisa estar se pensando, se constituindo e realizando ao mesmo tempo uma produção que se anuncia como científica. Estar em uma postura cartográfica é um exercício de formação, proporcionando olhar-se e publicizar-se em um envolvimento com a pesquisa.

\section{Estratégias de superação}

O que consideramos como superação? Consultando o dicionário de filosofia de Abbagnano (2007), superar não é somente mudar, mas conservar aspectos que se transformaram. Os pesquisadores demonstraram que não deixaram seu passado no esquecimento, constituíram tramas que se remodelavam a cada novo questionamento,

Nesse novo cenário, fui apresentada à cartografia, E, eis que de repente me vejo diante da necessidade de apreender o conceito de cartografia por um novo ângulo, por uma nova perspectiva. Tarefa, essa, nada fácil. A cada leitura realizada, a certeza de que ainda tenho muito que estudar, que ainda estou, tal qual a criança ao aprender a andar, nos primeiros passos; em um constante processo que alterna momentos de equilíbrios e desequilíbrios, acreditar que estou no caminho e, instantes depois, me ver perdida em um labirinto de autores e conceitos, 
procurando o fio de Ariadne que me levará ao encontro dos elementos necessários à definição do meu objeto, à constituição de meu novo projeto de pesquisa e ao emprego da cartografia como procedimento importante para o acompanhamento desse processo (Pesquisador 4).

A constituição do "novo" se realizava como um amálgama, não como camadas sendo sobrepostas, o novo sobre o velho, mas como fios que se enlaçam, enredam tramas e constituem possibilidades de caminhos.

Busquei mais informações em outras fontes, em especial artigos e percebi que se tratava de uma temática que estava sendo discutida há algum tempo. Na verdade, minhas buscas aumentaram minhas inquietações, mas foram diminuindo meu estranhamento. À medida que íamos discutindo, a cada encontro, os conceitos que o livro trazia, as peças foram começando a se encaixar. Percebi o quanto a cartografia nos aproxima do real, das percepções do mundo. O conhecimento é construído à medida que faço, que conheço. As relações são percebidas e não há uma linearidade durante a pesquisa. (Pesquisador 6).

Dentro do grupo de pesquisa existiam pessoas que já haviam incorporado esse conceito assim como sua forma e estruturação dentro de uma pesquisa qualitativa. Além de contar com essa experiência de alguns, contei também com o apoio dos outros pesquisadores que também buscavam essa apropriação do tema cartografia. Percebi que é preciso sim um esforço individual, mas com o suporte de um grupo que caminha no mesmo objetivo o fardo se torna um pouco mais leve (Pesquisador 6).

À medida que nos apropriamos dos posicionamentos dos autores, passamos a perceber a importância da postura cartográfica e o real significado do percurso investigativo para nosso objeto de estudo, bem como tínhamos a certeza que nossos conhecimentos precisavam e precisam ser fundamentados com leituras direcionadas e dialogadas. Minha dificuldade enfrentada sobre o estudo da Postura Cartográfica foi desconstruir as concepções já cristalizadas durante minha formação (Pesquisador 1). 
Conforme salientado por Passos e Barros (2009), a diretriz cartográfica se faz por pistas que orientam o percurso da pesquisa. Nesse sentido, Régis e Fonseca (2012) mencionam que uma dessas orientações diz respeito aos registros dos movimentos, dos encontros e desencontros, o que nos coloca em situação favorável para registrarmos aqui nesse relato, as dificuldades enfrentadas, as estratégias de superação e as aprendizagens proporcionadas àqueles que praticam a cartografia como referencial para a pesquisa (Pesquisador 5).

A citação dos autores estudados aparecia como "nós" que amarram ideias, significados eram constituídos, mas tudo sendo enlaçado com os objetivos e objetos de pesquisa. Não se podia pensar fora do que se vivia. Era um exercício de estar dentro, enredando tudo com tudo. Não é coisa fácil. Angustia. Desconforta. Sai da segurança e mergulha no fazer interpretando e justificando. Como afirmamos anteriormente, fazer-se.

As estratégias de superação estão sendo desenvolvidas nesses momentos de troca de saberes e nas discussões teóricas a respeito da importância da cartografia nas nossas pesquisas, nas perguntas e respostas esclarecedoras e outras a serem ainda respondidas ao longo de nossos estudos e pesquisas. Os estudos dos autores que refletem sobre a cartografia são determinantes para que possamos identificar e entender a estreita relação que existe entre a cartografia e a pesquisa investigativa, onde consideramos que para analisar sobre a formação, os saberes e as práticas dos professores dos cursos de licenciaturas será necessário conhecer o seu percurso, bem como sua trajetória pessoal e profissional (Pesquisador 1).

Devemos considerar que uma pesquisa já é um produto de trabalho e que estamos refletindo sobre as necessidades de quem realiza o ato da leitura dos resultados, mas devemos considerar também que o ato da feitura da pesquisa é exercício de produção e formação. Quando estamos tratando de estudantes de graduação e pós-graduação, estes estão em formação, não negando que um doutor, mestre, especialista e graduado 
também se encontra em formação quando realiza um ato de pesquisa. Nossa investigação considera as particularidades de pesquisadores que, na sua maioria, são profissionais no magistério e que estão realizando cursos de formação em níveis diferentes.

\section{Aprendizagens Proporcionadas}

Proporcionar desconforto. Soa estranho quando ciência parece representar segurança. Fazer ciência é mergulhar na dúvida e nos questionamentos. Quanto mais investigamos, parecem surgir novas dúvidas e a necessidade de mais estudos. Deixemos as verdades absolutas para os seguidores das religiões. Evitamos buscar dogmas.

Constato que a cartografia tem por vantagem a formação em processo e que as descobertas auxiliam pesquisador e sujeitos a refletirem acerca de sua postura pessoal e profissional, principalmente o que fazem e como fazem o desenvolvimento dos processos nas instituições. Entendo, então, que a cartografia se faz à medida que os percursos se desvelam. Dessa maneira, as escolhas das estratégias também acontecem durante o processo de conhecimento das trajetórias a serem cartografadas (Pesquisador 2).

Portanto, aprendemos que a pesquisa cartográfica se refere ao acompanhamento do processo formativo, diz respeito aos momentos do percurso dos professores antes e durante sua trajetória pessoal e profissional e também quando traçamos esse percurso realizando uma descrição detalhada desse processo utilizando as pistas metodológicas que vão direcionar o caminho a ser percorrido registrando todos os momentos subjetivos e as percepções do pesquisador e dos sujeitos investigados. Estamos aprendemos também que a cartografia é uma "teia de rizoma" porque envolve o olhar investigativo sobre o nosso próprio percurso e sobre os sujeitos da pesquisa, constituindo assim as teias de relacionamentos considerando seus diferentes contextos (Pesquisado 1 ). 
O que eu posso considerar como aprendizado com relação à cartografia é a ideia de caminho. Esta palavra me remete ao cotidiano da pesquisa. De fato, nós estamos sempre empreendendo passos investigativos. Esta perspectiva de trajetória foi o que mais me chamou atenção quando começamos as leituras sobre cartografia (Pesquisador 3).

Procuramos não comentar muito os resultados dos relatos referentes à categoria das aprendizagens proporcionadas. Acreditamos que os relatos se bastam. São explícitos, diretos e demonstram o que se viveu, sentiu, constituiu e fizemos juntos.

Quando precisamos orientar, compreender, usar ou mesmo criticar uma pesquisa, necessitamos conhecer os objetivos pretendidos, as fontes utilizadas, os métodos, os fundamentos teóricos, a temporalidade, a espacialidade e tudo mais que é requisito de uma investigação científica. Devemos compreender que tudo que contem em uma pesquisa, devidamente publicada, passou pelas escolhas de um ou mais pesquisadores. Se realizarmos perguntas como: por que foram escolhidas algumas fontes e não outras? O que motivou a escolha dos autores consultados? O que motivou as decisões do pesquisador no transcorrer das dificuldades enfrentadas? Qual a relação entre suas escolhas e suas experiências de vida? Todas estas perguntas auxiliam um leitor, no melhor entendimento de uma pesquisa, principalmente se tratarmos de uma pesquisa qualitativa.

\section{Conclusões}

Concluir parece atitude estranha para alguém que exercita a Postura Cartográfica. As dúvidas e questionamentos parecem nunca cessarem. Viver a angústia de fazer-se não é tarefa fácil e necessita exercitar-se.

Podemos chegar a algumas pistas, ou melhor, aprendizagens depois da análise dos discursos proferidos. Primeiramente o que foi vivenciado proporcionou o desconforto e a busca da constituição de tramas. Enredando e constituindo "ligações" a cada nova leitura, perguntas de outro pesquisador ou mesmo um questionar-se sobre por quê escolhi e fiz. 
A postura cartográfica motivou o espírito científico e gerou incertezas na busca do conhecimento. Existem pontos que foram apresentados como problemas, como a necessidade de estudar cada vez mais em um tempo tão exíguo como são nossos cursos de formação. Outro ponto que precisa ser mais bem trabalhado é a necessidade de exercitar uma escrita através de uma postura cartográfica. Normalmente não procuramos ser detalhistas e questionadores dos nossos próprios atos, quando produzimos atividades acadêmicas. Somos muitas vezes cobrados para sermos sucintos e diretos. Não que devamos ser prolixos ou demasiadamente detalhistas, mas precisamos relatar e questionar por que fizemos escolhas e tudo mais que compõe o ato de ser pesquisador.

O que nos guia como fundamento teórico para seguirmos uma Postura Cartográfica é acreditarmos que aprender está associado à busca de significados, à constituição de uma trama que se modela e fortalece através do entendimento dos sentidos. Como uma teia tridimensional, o conhecimento se constitui como trama, cada ponto da teia é transpassado por feixes de significado. São nós que amarram os feixes, que se cruzam em diferentes sentidos. O que o pesquisador necessita é constituir a trama da pesquisa, amarrando os sentidos e dando significado ao que faz. O pesquisador deve se fazer buscando interpretar os sentidos tomados e sendo produtor de um discurso que possa explicar o significado constituído, sendo ente que toma ciência do que faz a cada novo fazer, possibilitando críticas constantes e tomadas de decisões devidamente justificadas e fundamentadas. Não é exercício fácil. Alguns orientandos afirmaram que seria melhor definir tudo antes e seguir. Acreditamos que conhecer é ato de complexidade. Como afirmou Morin, "o conhecimento é, portanto, um fenômeno multidimensional, de maneira inseparável, simultaneamente físico, biológico, cerebral, mental, psicológico, cultura, social" (2015, p. 18).

São possibilidades apresentadas em uma escritura em que procuramos narrar e problematizar o que foi sendo exercitado em um grupo de pesquisadores que se faz e refaz a cada novo encontro/escrito com a Postura Cartográfica. 


\section{Referências}

ABBAGnANO, N. Dicionário de Filosofia. Trad. Alfredo Bosi. 5. ed. São Paulo: Martins Fontes, 2007.

BACHELARD, G. A formação do espírito científico. Rio de Janeiro: Contraponto, 1996.

DELEUZE, G; GUATTARI, F. Mil platôs: Capitalismo e esquizofrenia. São Paulo: Ed. 34, 2004. v. 1.

DINIZ, D. Carta de uma orientadora: o primeiro projeto de pesquisa. Brasília: Letras Livres, 2012.

GUSMÃO, L. O fetichismo do conceito: limites do conhecimento teórico na investigação social. Rio de Janeiro: Topbooks, 2012.

MAGALHÃES JUNIOR, A. G. Ao abrir dos olhos, a angústia ou quando da expulsão do paraíso: formação do professor pesquisador. In: MOREIRA SALES, J. Á.; BARRETO, M. C.; FARIAS, I. M. S. (Org.). Docência e formação de professores: novos olhares sobre temáticas contemporâneas. Fortaleza: EdUECE, 2009. p. 121-128.

MINAYO, M. C. de S. (Org.). Pesquisa Social: teoria, método e criatividade. 18. ed. Petrópolis: Vozes, 2001.

MORIN, E. O Método 3: conhecimento do conhecimento. Trad. Juremir Machado da Silva. 5. ed. Porto Alegre: Sulina, 2015. 286p.

PASSOS, E.; KASTRUP, V.; ESCÓCIA, L. da. (Org,). Pistas do método da cartografia: pesquisa-intervenção e produção da subjetividade. Porto Alegre: Sulina, 2015.

POPPER, K. A lógica da pesquisa científica. São Paulo: Cultrix, 2002.

ROLNIK, S. Cartografia sentimental, transformações contemporâneas do desejo. São Paulo: Estação Liberdade, 2014. 
TARDIF, M. Saberes profissionais dos professores e conhecimentos universitários: elementos para uma epistemologia da prática profissional dos professores e suas consequências em relação à formação para o magistério. Revista Brasileira de Educação, n. 13, p. 5-24, jan./abr. 2000.

Recebido: 24/09/2018

Received: 09/24/2018

Recibido: 24/09/2018

Aprovado: 28/11/2018 Approved: $11 / 28 / 2018$ Aprobado: 28/11/2019 